\title{
Effects of free leucine supplementation and resistance training on muscle strength and functional status in older adults: a randomized controlled trial
}

Clinical Interventions in Aging

13 April 2015

Number of times this article has been viewed

\author{
Joan Trabal' \\ Maria Forga' \\ Pere Leyes' \\ Ferran Torres ${ }^{2,3}$ \\ Jordi Rubio ${ }^{4}$ \\ Esther Prieto ${ }^{5}$ \\ Andreu Farran-Codina ${ }^{6}$ \\ 'Department of Endocrinology \\ and Nutrition, Hospital Clínic \\ Universitari de Barcelona, Barcelona, \\ Catalonia, Spain; ${ }^{2}$ Biostatistics and \\ Data Management Core Facility, \\ IDIBAPS, Hospital Clinic Universitari \\ de Barcelona, Barcelona, Catalonia, \\ Spain; ${ }^{3}$ Biostatistics Unit, School \\ of Medicine, Universitat Autònoma \\ de Barcelona, Barcelona, Catalonia, \\ Spain; ${ }^{4}$ Residencia Ballesol Almogavers, \\ Grupo Ballesol, Barcelona, Catalonia, \\ Spain; ${ }^{5}$ Centre de Rehabilitacio, \\ Fundació Amiba, Badalona, Catalonia, \\ Spain; ${ }^{6}$ Department of Nutrition and \\ Food Science, Faculty of Pharmacy, \\ Universitat de Barcelona, Barcelona, \\ Catalonia, Spain
}

Objective: To assess the effect of free leucine supplementation combined with resistance training versus resistance training only on muscle strength and functional status in older adults.

Methods: This was a randomized, double-blind, placebo-controlled, parallel study with two intervention groups. Thirty older adults were randomly assigned to receive either $10 \mathrm{~g}$ leucine/ day (leucine group [LG], $n=15$ ) or a placebo (control group [CG], $n=15$ ), plus resistance training over a 12-week period. Maximal overcoming isometric leg strength, functional status, nutritional status, body composition, health-related quality of life, depression, and dietary intake were assessed at 4 and 12 weeks. Missing data at 12 weeks were handled using mixed models for repeated measurements for data imputation.

Results: Twenty-four subjects completed the 4-week assessment and eleven completed the 12-week intervention. Clinically significant gains were found in isometric leg strength at both assessment time points. Analysis of the effect size also showed how participants in LG outperformed those in CG for chair stands and the timed up and go test. No significant changes were observed for the rest of the outcomes.

Conclusion: Our combined analysis showed moderate changes in isometric leg muscle strength and certain components of functional status. The magnitude of changes found on these outcomes should be qualified as a positive effect of the concomitant intervention.

Keywords: aged, elderly, strength training, amino acid, functionality

\section{Introduction}

Sarcopenia is one of the main causes for an increased risk of physical disability and poor quality of life. ${ }^{1}$ The reduction in functional capacity that is derived from the loss of muscle strength may result in increased dependency, hospitalization, and institutionalization, ${ }^{2}$ and is a likely progression to physical frailty. ${ }^{3}$

One of the processes involved in the pathophysiology of sarcopenia seems to be disruption in the regulation of muscle protein turnover. ${ }^{4}$ Several studies have shown how aged muscle is less responsive to the anabolic stimuli of amino acids and exercise, ${ }^{5,6}$ a concept now commonly referred to as anabolic resistance. ${ }^{7}$ However, some studies have observed that this resistance can be overcome by increasing the leucine content of meals, ${ }^{8}$ since the enhanced response in protein synthesis to greater amino acid availability is mainly produced by leucine independently of other amino acids. ${ }^{9}$ It has been hypothesized that to maximize muscle protein synthesis in older adults, a "leucine threshold" must be surpassed. ${ }^{10}$ This threshold would differ between young
Correspondence: Joan Trabal Unitat de Nutrició i Dietètica Clínica, Servei d'Endocrinologia i Nutrició, Hospital Clínic Universitari de Barcelona, Villarroel, I70, 08036, Barcelona, Catalonia, Spain

Tel +34932275400 ext 3424

$\mathrm{Fax}+34932275454$

Email joantrabal@gmail.com 
and older adults. Studies in young adults have shown that $1 \mathrm{~g}$ of leucine concomitant with resistance exercise is enough to stimulate muscle protein synthesis. ${ }^{11,12}$ On the other hand, older adults would require over $2 \mathrm{~g}$ of leucine to stimulate muscle protein synthesis to the same extent. ${ }^{13}$

Given the fact that resistance training is still considered the most effective and safe treatment for improving muscle strength and function in older adults, ${ }^{14,15}$ even at a very advanced age, ${ }^{16}$ some studies investigated the effects of protein supplementation and resistance training on these outcomes. However, the results of interventions based on resistance training and classical protein supplementation in subjects with sufficient protein intake are still controversial. ${ }^{17-19}$

Thus, engaging in a program of resistance training seems clearly desirable for ameliorating muscle strength, and while the effects of leucine on improving muscle protein synthesis seem promising, its effects on muscle strength and functionality are still under discussion. Very few studies have investigated the effects of a combined intervention with high leucine supplementation and resistance exercise on outcomes such as strength or functionality in older people.
Therefore, the aim of this study was to assess the effects of an intervention with free leucine supplementation combined with resistance training on muscle strength and functional status in older adults.

\section{Methods Subjects}

From December 2009 to December 2012, a total of 82 older adults over 70 years of age were screened for inclusion criteria in different nursing homes and adult day care centers within the Barcelona metropolitan area; of these, 30 subjects were recruited to participate in the study. The exclusion criteria were: chronic kidney disease, a disability that did not allow the practice of exercise (eg, a fractured limb during the last 6 months), performing resistance training on a regular basis, dietary protein restriction, following a low-calorie diet for weight loss, the need for oral nutritional supplementation or enteral nutrition, the need for drugs with orexigenic or anabolic effects, and long-term use of corticosteroids. Figure 1 illustrates the subject screening process, randomization to treatments, and time points of assessment over the course of the 12-week intervention. All subjects were given oral

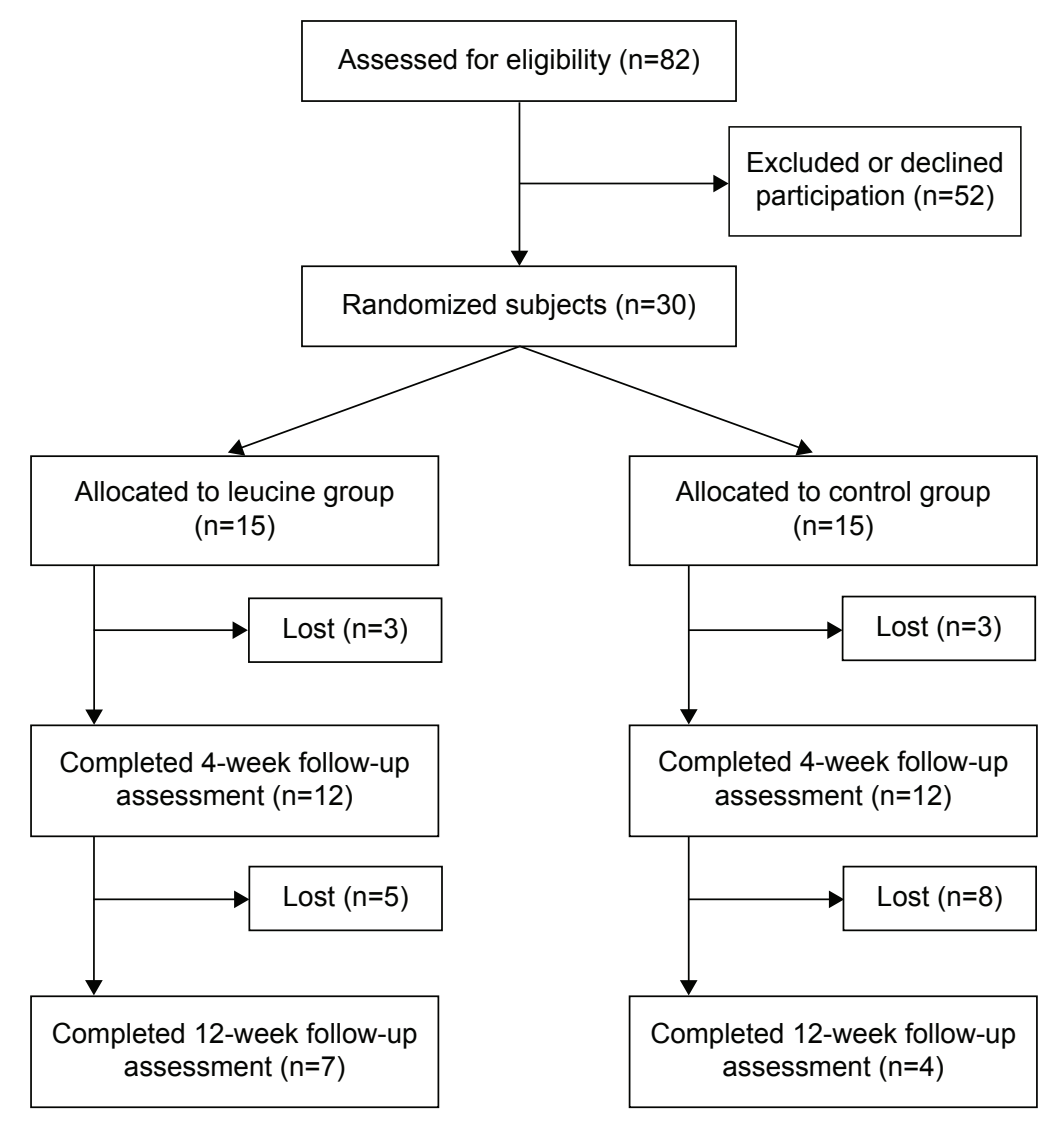

Figure I Flowchart of study groups at different time points. Note: Subject dropout is reported as "lost". 
and written information about the nature of the study before a signed informed consent was obtained. The procedures used were in accordance with ethical standards and with the 2008 Helsinki Declaration. Study approval was granted by the Ethics Committee of Clinical Research of the Hospital Clínic Universitari de Barcelona.

\section{Study design}

This was a randomized, double-blind, placebo-controlled, parallel study with two intervention groups. Participants were randomized by blocks of ten subjects and assigned to their respective groups. Subjects were supplemented daily with free leucine or placebo during a 12-week intervention period. Throughout this period, all participants followed an adapted exercise program for older adults 4 days a week. Participants were assessed for all variables at baseline and after 4 and 12 weeks of intervention.

\section{Supplementation}

Subjects were supplemented either with $10 \mathrm{~g}$ /day of leucine (L-Leucine; Nutricia, Liverpool, UK) or the same amount of maltodextrin as a placebo (Maxijul; Nutricia). A study by Yang et al found that although $20 \mathrm{~g}$ of whey protein was capable of surpassing the "leucine threshold" and increased rates of myofibrillar muscle protein synthesis in older adults, the ingestion of $40 \mathrm{~g}$ of whey protein increased exercisestimulated rates of muscle protein synthesis to an even greater extent. ${ }^{13}$ Since $40 \mathrm{~g}$ of whey protein is equivalent to $\geq 4 \mathrm{~g}$ of leucine, in our study, participants ingested $5 \mathrm{~g}$ twice a day, 60 minutes after the main meals (lunch and dinner), provided in a double-blinded manner. Both supplement and placebo were accompanied with a lemon and lime flavor (Flavor Sachets; Nutricia) to disguise the characteristic taste of leucine.

\section{Exercise program}

The exercise program consisted of three sessions of progressive resistance training adapted for older adults and one session of balance exercises per week during the 12-week period of intervention. Each progressive resistance session started with a 5-minute warm-up, 30 minutes of strength training, and 5 minutes of cool down. Most of the exercises were executed while seated or with the use of a chair as a support aid. Participants started with two sessions of familiarization and in the next sessions, were instructed to complete one set of eight repetitions of each exercise. When exercises were properly executed without significant fatigue, the number of repetitions and sets were increased until the participants achieved two sets of 15 repetitions, which usually represented an intensity of $65 \%$ of the maximum number of repetitions. There were rest intervals of 3 minutes between each set of repetitions. The exercise routine was mainly focused on improving strength in the lower extremities; it included chair squats, leg curls, leg extensions, toe stands, as well as wall push-ups. Balance training routines included side leg raises, back leg raises, hip flexions, and walking heel to toe. The exercise program was based on the recommendations given by the American College of Sports Medicine ${ }^{20}$ and was conducted under the supervision of physiotherapists to ensure that the exercises were carried out safely and effectively.

\section{Muscle strength}

Maximal overcoming isometric leg strength was used as the primary outcome measure. Assessment was performed with both legs at $130^{\circ}$ leg flexion and measured with a dynamometer (Baseline ${ }^{\circledR}$ Back-Leg-Chest Dynamometer; Fabrication Enterprises Inc., Elmsford, NY, USA). A demonstration was carried out by one of the researchers on how to properly execute the test; participants also familiarized and pre-tested the dynamometer before performing the test. Subjects were given up to three attempts to achieve their maximal strength, with a time limit of 5 seconds per attempt; the highest value was taken for analysis.

\section{Functional status}

The functional status of patients was assessed using the physical performance battery (PPB) proposed by Avila-Funes et al. ${ }^{21}$ The PPB specifically assesses lower extremity function with four tests, including a standing balance test, a 4 m walking speed test, the ability to rise from a chair five times, and the timed up and go (TUG) test. Participants were instructed by one of the researchers on how to properly perform each test before the test was executed. Higher times on the standing balance test and lower times on the remaining tests indicate better function. The Barthel Index was also used as a measure of functionality. ${ }^{22}$ This tool assesses the activities of daily living of individuals on a scale ranging from 0 to 100 points. Low scores indicate high dependency and high scores show a more or less intact ability to care for oneself.

\section{Nutritional status and body composition}

The Mini Nutritional Assessment (MNA) was used to assess nutritional status. ${ }^{23}$ Subjects were classified as being of normal nutritional status ( $>24$ points), at risk of malnutrition (17-23.5 points), or malnourished ( $<17$ points). Anthropometric parameters were obtained by a trained researcher using standard techniques, including: body weight, height, 
body mass index (BMI), waist circumference, triceps skin fold, mid-upper arm muscle area (MUAMA), and calf circumference.

\section{Health-related quality of life}

The 36-Item Short-Form Health Survey (SF-36) questionnaire was used to assess health-related quality of life (HRQOL). The SF-36 consists of eight multi-item scales reflecting physical and mental HRQOL: ten items for physical function (PF), which measures limitation in PF; four items for role physical, which measures role limitations due to PF; two items for bodily pain, measuring the impact of pain on daily activities; five items for general health; four items for vitality; five items for mental health; two items for social function; three items for role emotional, measuring role limitations due to emotional function; and one transition item not used in the calculation. The raw scores were transformed; the final scores for each of the eight items range from 0 to 100 , with 0 signifying the worst status and 100 signifying the best status. The SF-36 has been validated for use within a Spanish population. ${ }^{24}$

\section{Depression assessment}

The short form of the Geriatric Depression Scale (GDS-15) was used to assess the presence of depression. This screening tool is a 15-item questionnaire that helps to identify depression in older adults, and has been validated for use within a Spanish population. ${ }^{25}$ Subjects were classified as having no depression ( $0-5$ points), being suggestive of depression (6-9 points), and having depression ( $>10$ points).

\section{Dietary intake}

Food intake was assessed with the use of 3-day food records (including a weekend day) at every time point; subjects were previously instructed by a dietitian on how to record food and beverage intake. Mean total energy and protein intakes were calculated using the software ADN (v1.0; Faculty of Pharmacy, Universitat de Barcelona, Catalonia, Spain).

\section{Supplementation and exercise compliance}

Supplement intake and exercise compliance were visually supervised by nursing staff and physiotherapists, respectively. Daily compliance records for supplementation and exercise were obtained. The ratio of supplement compliance at the 4-week follow-up assessment was $0.80 \pm 0.14$ in the leucine group (LG) and $0.95 \pm 0.05$ in the control group (CG); exercise compliance was $0.98 \pm 0.03$ in $L G$ and $0.96 \pm 0.08$ in CG.

\section{Data analysis}

Continuous variables were described as means and 95\% confidence intervals (CIs) or standard deviation, and categorical variables as frequencies or otherwise specified. For Gaussian variables repeatedly measured over time, a restricted maximum likelihood-based repeated measures approach (ie, mixed models for repeated measurements [MMRM]) was applied to estimate baseline-adjusted least square means and $95 \% \mathrm{CI} ;{ }^{26}$ missing data at 12 weeks were assumed to be missing at random and were adequately extrapolated by the MMRM model. For non-Gaussian continuous variables, the Mann-Whitney-Wilcoxon test was performed for betweengroup comparisons. Within-group baseline changes were analyzed with the Wilcoxon signed-rank test for paired data. Categorical variables were analyzed using Fisher's exact test. We also report the effect size for a better interpretation of the magnitude of the difference between the study groups. Data analysis was performed with the use of the statistical analysis software R (v3.0.1; The R Foundation for Statistical Computing, Vienna, Austria) and SAS (v9.2; SAS Institute Inc., Cary, NC, USA). For all statistics, significance was set at the $5 \%$ two-sided level.

\section{Results}

\section{Patient characteristics}

Twenty-four of the 30 included subjects (16 women and eight men) completed the 4-week follow-up assessment, and only eleven subjects from the original sample completed the 12-week intervention. Figure 1 shows the loss of participants during the study period. Subjects dropped out due to the following circumstances: in LG, seven subjects did not tolerate the supplement and one mentioned physical pain due to exercise; in $C G$, four subjects refused to take the established amount of supplement, four developed a major health problem, two did not comply with the exercise program, one mentioned physical pain due to exercise, and one voluntarily dropped out of the study without a specific reason.

Baseline characteristics for the 24 subjects are shown in Table 1. There were no between-group differences for all variables at baseline between the completer sample and the initial sample of 30 patients.

\section{Muscle strength}

Table 2 shows the changes for maximal overcoming isometric leg strength over the study period. Analysis of changes in strength revealed a possible beneficial effect for this outcome in LG when compared to CG at both time 
Table I Baseline characteristics of participants

\begin{tabular}{|c|c|c|}
\hline & $\begin{array}{l}\text { Control } \\
(n=12)\end{array}$ & $\begin{array}{l}\text { Leucine } \\
(n=\mid 2)\end{array}$ \\
\hline Age (years) & $84 \pm 4$ & $85 \pm 8$ \\
\hline Dynamometry (kg) & $27.5 \pm 15.7$ & $29.9 \pm 25.3$ \\
\hline Standing balance (seconds) & $1.7 \pm 1.7$ & $4.4 \pm 7.5$ \\
\hline 4 m walk (seconds) & $5.0 \pm 1.2$ & $5.8 \pm 1.8$ \\
\hline Chair stands (seconds) & $14.9 \pm 3.9$ & $20.8 \pm 8.2$ \\
\hline Timed up and go (seconds) & $16.9 \pm 6.1$ & $18.2 \pm 5.5$ \\
\hline Barthel Index & $90 \pm 12$ & $87 \pm 15$ \\
\hline Weight (kg) & $62.9 \pm 15.4$ & $64.6 \pm 9.4$ \\
\hline BMI $\left(\mathrm{kg} / \mathrm{m}^{2}\right)$ & $26.0 \pm 5.2$ & $26.6 \pm 4.4$ \\
\hline Triceps skinfold (mm) & $20.3 \pm 8.3$ & $21.7 \pm 6.2$ \\
\hline MUAMA (mm) & $21.6 \pm 3.3$ & $20.8 \pm 2.4$ \\
\hline Calf circumference (mm) & $33.4 \pm 4.2$ & $33.3 \pm 2.6$ \\
\hline Waist circumference $(\mathrm{cm})$ & $96.3 \pm 15$ & $97.5 \pm 8$ \\
\hline MNA & $23.5 \pm 5$ & $24.0 \pm 3$ \\
\hline Barthel Index & $90.4 \pm 12$ & $87.1 \pm 15$ \\
\hline GDS & $5.0 \pm 3.5$ & $5.4 \pm 2.8$ \\
\hline Energy requirements (kcal) & $1,489 \pm 328$ & $1,560 \pm 300$ \\
\hline Protein requirements $(\mathrm{g})$ & $64 \pm 16$ & $67 \pm 9$ \\
\hline Energy intake (kcal) & $1,574 \pm 200$ & $1,694 \pm 257$ \\
\hline Protein intake $(g)$ & $76 \pm 12$ & $8 I \pm 6$ \\
\hline
\end{tabular}

Note: All values are means \pm standard deviations.

Abbreviations: BMI, body mass index; GDS, Geriatric Depression Scale; MNA Mini Nutritional Assessment; MUAMA, mid-upper arm muscle area.

points of assessment. The magnitude of the effect size was approximately 0.6 at both time points of assessment, which can be interpreted as if the average participant in LG scored higher than $73 \%$ of the score for a participant in CG that was initially equivalent.

\section{Functional status}

The results of the intervention on the four tests that assess functional status can be seen in Table 2. No statistically significant changes were found for most of the outcomes that assessed functional status, except for the TUG test at 12 weeks. The magnitude of the difference of test times between groups for the chair stands and the TUG test at 12 weeks was -0.558 and -0.732 , respectively, both in the range of having a medium effect. The effect size for the rest of the functional tests was below 0.5 for both groups, which can be considered a small change. Barthel Index scores were over 90 in both groups at both assessment time points (data not shown).

\section{Nutritional status and body composition}

Table 3 shows the changes for body composition and nutritional status of participants. No significant changes were found for most of the body composition outcomes. Although the analysis showed statistically significant changes for the MUAMA, the clinical significance of those changes is negligible and should not be taken into consideration. The nutritional status of participants according to MNA remained stable throughout the intervention.

\section{Health-related quality of life and depression assessment}

Figure 2 shows the results of the intervention on HRQOL. There were no differences between groups for all domains of HRQOL throughout the intervention. Similarly, the analysis of the GDS-15 scores did not find any significant changes on this outcome (data not shown).

\section{Dietary intake}

Nutritional analysis did not show any between-group differences for energy or protein intake (Table 3). Energy intake remained unchanged in both groups. A $16 \%$ increase in protein intake was observed at 4 weeks only for CG compared to baseline $(P=0.014)$. Both groups fulfilled their energy and protein requirements. At baseline, daily protein intake averaged $1.25 \mathrm{~g} / \mathrm{kg} /$ day and $1.20 \mathrm{~g} / \mathrm{kg} /$ day for LG and CG, respectively. At the first follow-up, this increased to 1.28 $\mathrm{g} / \mathrm{kg} /$ day in $L \mathrm{G}$ and $1.4 \mathrm{~g} / \mathrm{kg} /$ day in CG.

\section{Discussion}

Our study aimed to assess the effects of an intervention with free leucine supplementation combined with resistance training on muscle strength and functional status in older adults. The results of our study suggest a moderate beneficial effect of the intervention on muscle strength and certain components of functional status.

Previous studies have observed that increasing the leucine content of a meal increases the postprandial muscle protein synthetic response in older adults. ${ }^{8,9,27}$ Moreover, short-term leucine supplementation studies in rats have shown how this amino acid improves strength recovery after a lesion or a period of immobilization. ${ }^{28,29}$ Therefore, some authors have suggested that long-term leucine supplementation during main meals might help to increase muscle mass and strength in older people. ${ }^{30}$ Although previous longitudinal studies with leucine supplementation in older adults have not found increases in muscle mass or strength, ${ }^{31,32}$ these studies did not concomitantly use leucine supplementation with resistance training. Therefore, to our knowledge, this is the first randomized controlled trial that has combined high doses of free leucine supplementation and resistance training to assess its effects on muscle strength and functional status in older adults. 


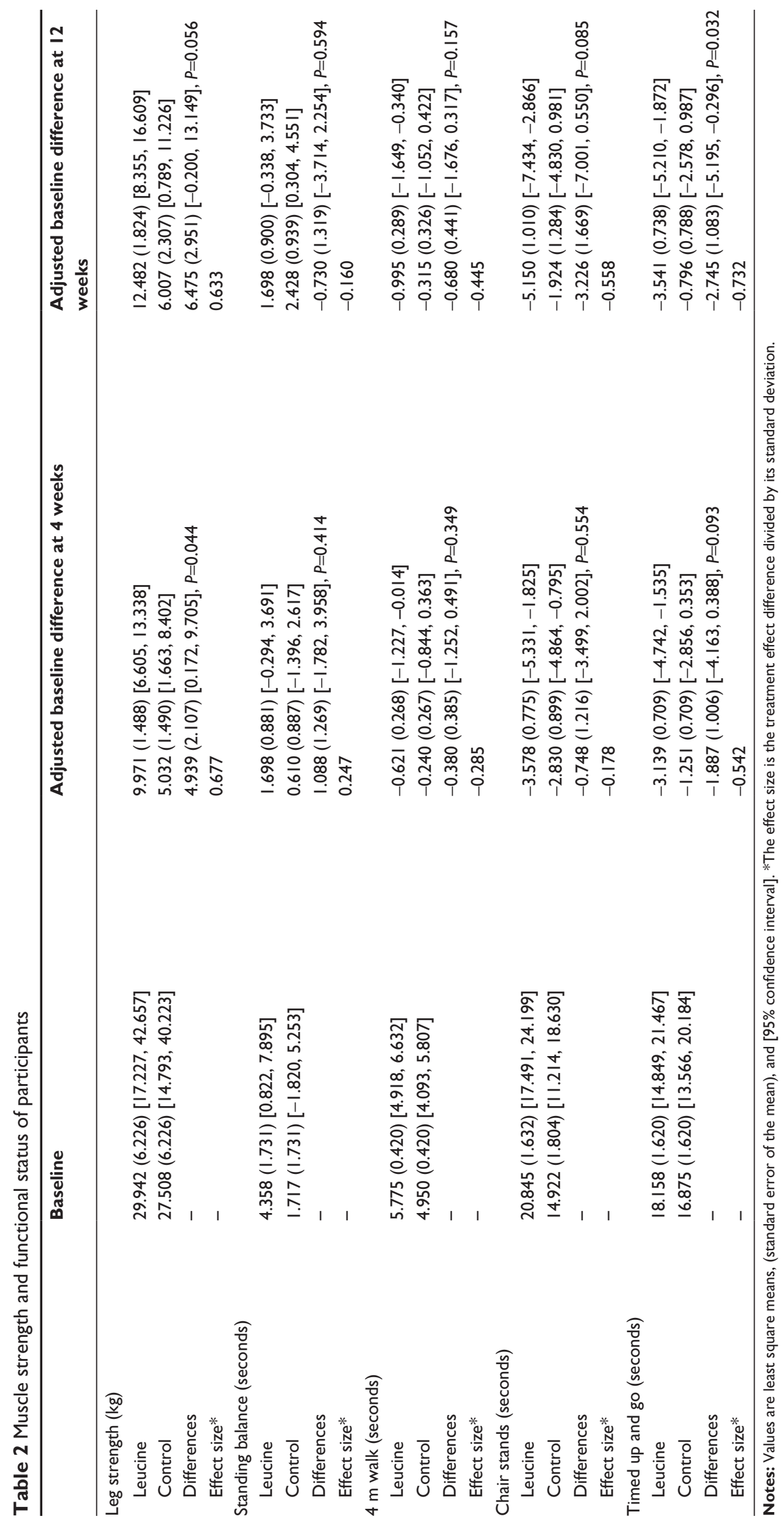




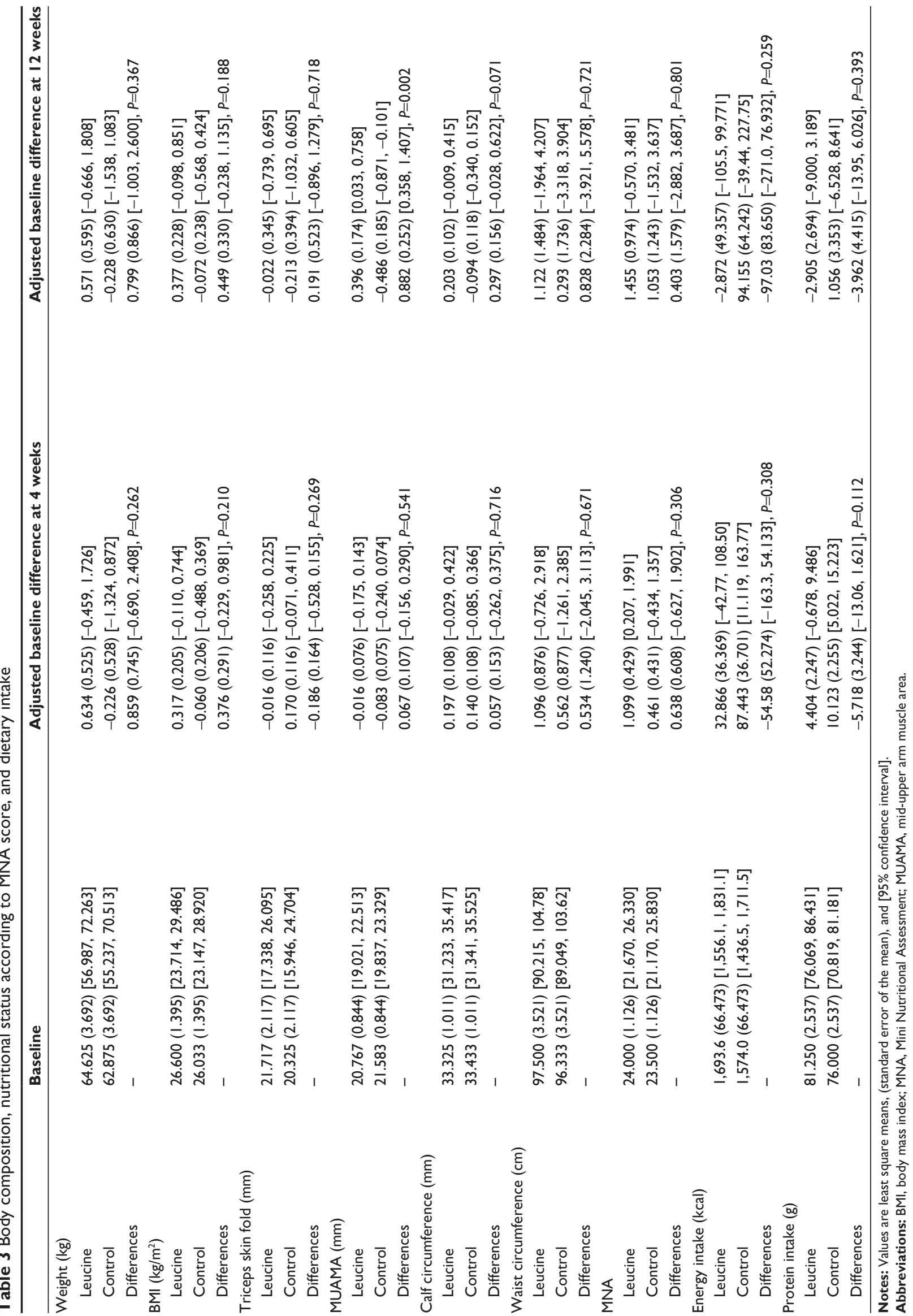


A

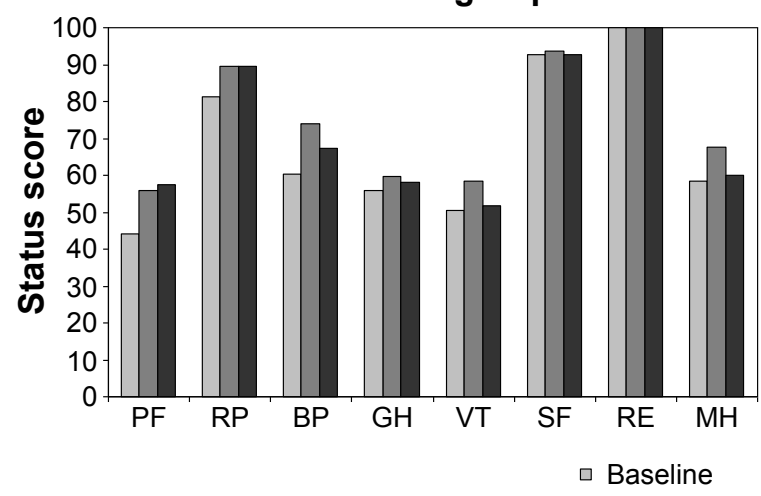

B

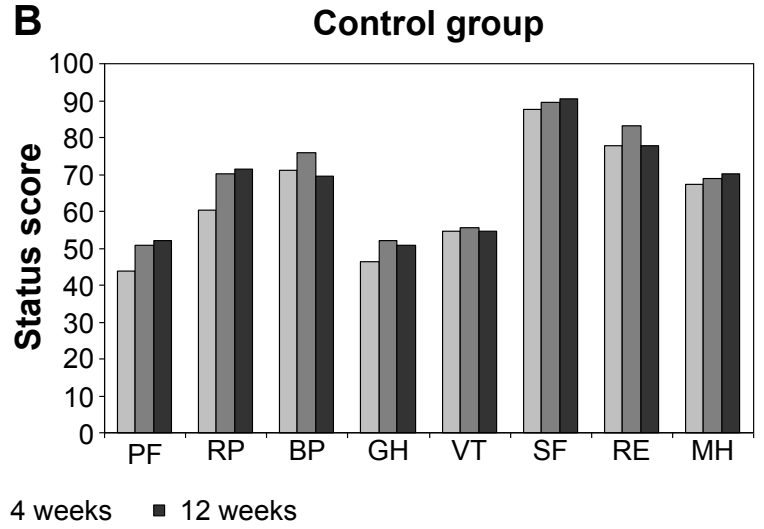

Figure 2 Health-related quality of life according to the SF-36 questionnaire.

Notes: Health-related quality of life intra-group scores for both groups of study (A, B). The PF domain shows an increase $>25 \%$ in the leucine group after the intervention, that increase in the control group was $16 \%$.

Abbreviations: BP, bodily pain; GH, general health; MH, mental health; PF, physical function; RE, role emotional; RP, role physical; SF, social function; SF-36, 36-Item ShortForm Health Survey; VT, vitality.

\section{Muscle strength and functional status}

In the present study, we observed substantial gains in leg muscle strength during both time points of assessment for LG compared to CG. Although this outcome did not reach the established limit for statistical significance at 12 weeks, between-group differences should be considered clinically significant. Further, given that effect sizes at both time points were of moderate magnitude, these changes are noteworthy. Regarding functionality, only one of the four functional tests, the TUG test, showed a statistically significant difference. Nevertheless, when looking to the magnitude of changes, the supplemented group moderately outperformed the placebo group in the TUG and the chair stands tests. The effect sizes for the standing balance and $4 \mathrm{~m}$ walking test were small. These differences in magnitude between functional tests could be explained by the fact that the standing balance and $4 \mathrm{~m}$ walking test do not rely on strength in the lower extremities as much as the chair stands and the TUG test.

Previous studies conducted in older adults with resistance training and amino acid supplementation have not been able to demonstrate significant effects regarding gains in muscle strength and functional status. In a study by Godard et al, $12 \mathrm{~g}$ of essential amino acids (EAA) plus carbohydrates were given daily during a 12 -week resistance training program three times a week in older men. Although the intervention increased muscle strength in the experimental and control groups (both with resistance training) compared to baseline, no between-group differences were found..$^{33}$ In a more recent study by Kim et al, after a 12-week intervention that included strengthening, balance, and gait training twice a week plus $6 \mathrm{~g} /$ day of EAA supplementation in sarcopenic women, there were improvements in leg extension strength and walking speed, compared to baseline. However, between-group comparisons did not reveal differences in strength or functional outcomes between the EAA + resistance training group and the resistance training only or EAA only groups. ${ }^{34}$

In studies with resistance training in young people, improvements in muscle strength were seen with $4 \mathrm{~g}$ of free leucine/day, ${ }^{35}$ but not with $30 \mathrm{~g}$ EAA/day supplementation. ${ }^{36}$ Similarly, in a study consisting of 28 days of bed rest in young individuals, muscle strength improved after 14 days of resistance training, but the addition of $15 \mathrm{~g} /$ day of EAA supplementation did not result in greater gains. ${ }^{37}$

A long known effect of resistance training is the neural adaptations that it produces in skeletal muscle after only a few weeks of training, with an absence of significant hypertrophy.$^{38}$ Although the significant improvements found in muscle strength and some functional parameters could be related to this effect, it has to be taken into account that these improvements should also be present in CG. Therefore, we can hypothesize that some other muscular adaptations that might help to explain these differences could be attributed to leucine. ${ }^{29}$

Different factors could contribute to the contradictory results found between the cited literature and our results. One possible factor might be the amino acid formulation of the supplements and their leucine content. Leucine acts as a key trigger for postprandial stimulation of muscle protein synthesis and it appears that there is a stepwise increase of synthesis when blood leucine concentration rises after absorption. ${ }^{13}$ The EAA formulations used in the studies with older adults by Godard et al and Kim et al provided $2.24 \mathrm{~g}$ and $2.52 \mathrm{~g}$ of leucine/day, respectively. ${ }^{33,34} \mathrm{In}$ the studies with 
young individuals, $5.7 \mathrm{~g},{ }^{36} 4 \mathrm{~g},{ }^{35}$ and $2.8 \mathrm{~g}^{37}$ of leucine/day were provided. In our study, we provided $10 \mathrm{~g}$ leucine/day, and although the compliance reduced the mean intake to $8 \mathrm{~g} /$ day, it was still higher than any of the cited studies. Only one long-term study in older adults provided similar doses of leucine ( $7.5 \mathrm{~g} /$ day), without changes in skeletal muscle mass or strength when compared to placebo, although the intervention did not include resistance training. ${ }^{31}$ Therefore, we believe that these high doses of leucine supplementation helped to maximize the anabolic stimulus elicited by resistance training. Another proposed factor could be amino acid kinetics, since free leucine absorption is faster than the absorption of amino acids released after gastric emptying and protein digestion in the small intestine, and thus produces its anabolic stimulating effects long before there is enough availability of dietary amino acids. ${ }^{39}$ The cited studies had different patterns of intake for the amino acid supplementation; in three studies, EAA intake was immediately after the training session or with meals; ${ }^{33,35,36}$ in one study, 5 minutes before exercise; ${ }^{37}$ and in another study, was not specified. ${ }^{34}$ In our study, we tried to address this issue by delaying the time of leucine ingestion after the main meals. Moreover, we chose to group leucine intake into two meals, since in Spain, most of the daily protein intake is evenly distributed over lunch and dinner.

\section{Nutritional status and body composition}

Neither nutritional status nor body composition significantly changed over the duration of the intervention. This is to be expected in a short intervention in subjects that mostly had good nutritional status. Regarding body composition, it has been shown that a minimum of 6 weeks of supplementation and exercise are needed to observe measurable increases in muscle mass. ${ }^{40}$ Further, anthropometry is a low sensitivity tool to detect changes in certain aspects of body composition; the setting of our study did not allow for more sensitive methods such as dual-energy X-ray absorptiometry.

\section{Health-related quality of life and depression assessment}

Likewise, neither HRQOL nor depression were affected by the intervention. It is reasonable to think that the lack of differences in PF between groups can be attributed to a lower sensitivity of the HRQOL questionnaire compared to a battery performance test specifically designed to measure changes in functional status. Nevertheless, previous resistance training studies in older adults have not found changes in HRQOL or depression assessed with the SF-36 and the GDS-15 questionnaire. ${ }^{41,42}$

\section{Dietary intake}

Regarding food intake, LG and CG fulfilled energy requirements and protein intake was in accordance with recent recommendations for older adults in both groups. ${ }^{43}$ Therefore, we consider it irrelevant that increased protein intake was found at 4 weeks in CG, as LG was the group that experienced a greater effect on muscle strength.

\section{Limitations of the study}

The main limitation of the study is the loss to follow-up, with a considerable reduction in sample size during the study period, which limited sensitivity for detecting statistically significant changes. On one hand, we tried to minimize this limitation with data imputation analysis for missing data at 12 weeks. However, our results need to be carefully interpreted because no statistical method can meet the consequent uncertainty about the treatment effect and guarantee results free of bias. On the other hand, we analyzed the effect size of the main outcomes, which allows us to transform abstract statistical significance testing to concrete measures of difference. Since statistical significance is highly dependent on sample size, we believe that the results provided by the effect size analysis provide a better understanding of the real effect of the intervention on leg strength and functional status. Recruiting problems and loss of participants can be attributed to different causes; one of these causes is the difficulty of studying older adults, as has been previously reported ${ }^{44}$ Some individuals did not understand the importance of complying with the intervention, whether it was the supplementation or the exercise training, which represented a breach of the study protocol and resulted in exclusion. Also, the advanced age of the studied sample caused some participants to dropout before the end of the intervention due to health issues or problems with the exercise program. It should also be noted that all the discontinuations due to problems with the supplement occurred in LG. Although both supplements were blinded with the use of flavoring, the number of participants that did not tolerate the free leucine supplement was important. This leads us to believe that free leucine might not be a valid approach beyond the research setting; leucine-rich proteins (eg, whey protein) may be more tolerable in the clinical practice. The lack of a sedentary control group receiving leucine might also constitute a limitation of the study, since it did not allow us to observe if leucine alone would have had any positive effects. Although, as it has been previously 
pointed out, studies using leucine supplementation alone have not found any significant effects on muscle strength in older adults.

\section{Conclusion}

In our study, we observed moderate changes in isometric leg muscle strength, as well as the chair stand and TUG tests. The magnitude of changes found on these outcomes should be qualified as a positive effect, even though some results did not achieve statistical significance. More efforts should be made to study the effect of nutritional interventions with amino acids alongside resistance or power training on muscle strength and functional status in older adults, with larger samples that may allow for generalization of results. Although the study of gains in muscle mass is still relevant, only the assessment of crucial outcomes such as muscle strength and functional status will address clinical problems like the increased dependency that many older adults experience. We can hypothesize that malnourished individuals, frail older adults, or older patients that suffer long periods of bed rest may benefit from long-term interventions with leucine-rich supplementation and resistance training. A great effort and proper planning will be essential to overcome the challenges that the study of undernourished and/or frail populations might represent.

\section{Acknowledgments}

We are especially grateful for the cooperation of the subjects that made this study possible. We also want to particularly thank the generous collaboration of the physiotherapists that made possible the high exercise compliance, as well as the rest of the teams of Residencias Ballesol and Fundació Amiba Badalona: Jorgina Martin, Joaquima Olm, Aida Hernanz, Sergi Garcia, Maria Berenguer, Martina Muñoz, Cristina Sanguino, Ana Leon, Coral Fernandez, and Marta Toledano. We finally thank Nutricia Advanced Medical Nutrition, for their generous collaboration, supplying us with the study supplementation. The authors declare that no sources of funding were received for this study.

\section{Disclosure}

The authors report no conflicts of interest in this work.

\section{References}

1. Cruz-Jentoft AJ, Baeyens JP, Bauer JM, et al; European Working Group on Sarcopenia in Older People. Sarcopenia: European consensus on definition and diagnosis: Report of the European Working Group on Sarcopenia in Older People. Age Ageing. 2010;39(4):412-423.

2. Clark BC, Manini TM. Functional consequences of sarcopenia and dynapenia in the elderly. Curr Opin Clin Nutr Metab Care. 2010;13(3): 271-276.
3. Pel-Littel RE, Schuurmans MJ, Emmelot-Vonk MH, Verhaar HJ. Frailty: defining and measuring of a concept. J Nutr Health Aging. 2009; 13(4):390-394.

4. Volpi E, Mittendorfer B, Rasmussen BB, Wolfe RR. The response of muscle protein anabolism to combined hyperaminoacidemia and glucose-induced hyperinsulinemia is impaired in the elderly. J Clin Endocrinol Metab. 2000;85(12):4481-4490.

5. Cuthbertson D, Smith K, Babraj J, et al. Anabolic signaling deficits underlie amino acid resistance of wasting, aging muscle. FASEB $J$. 2005;19(3):422-424.

6. Kumar V, Selby A, Rankin D, et al. Age-related differences in the dose-response relationship of muscle protein synthesis to resistance exercise in young and old men. $J$ Physiol. 2009;587(Pt 1): 211-217.

7. Rennie MJ. Anabolic resistance: the effects of aging, sexual dimorphism, and immobilization on human muscle protein turnover. Appl Physiol Nutr Metab. 2009;34(3):377-381.

8. Katsanos CS, Kobayashi H, Sheffield-Moore M, Aarsland A, Wolfe RR. A high proportion of leucine is required for optimal stimulation of the rate of muscle protein synthesis by essential amino acids in the elderly. Am J Physiol. 2006;291(2):E381-E387.

9. Rieu I, Balage M, Sornet C, et al. Leucine supplementation improves muscle protein synthesis in elderly men independently of hyperaminoacidaemia. J Physiol. 2006;575(Pt 1):305-315.

10. Breen L, Phillips SM. Skeletal muscle protein metabolism in the elderly: interventions to counteract the "anabolic resistance" of ageing. Nutr Metab (Lond). 2011;8(1):68.

11. Tang JE, Manolakos JJ, Kujbida GW, Lysecki PJ, Moore DR, Phillips SM. Minimal whey protein with carbohydrate stimulates muscle protein synthesis following resistance exercise in trained young men. Appl Physiol Nutr Metab. 2007;32(6):1132-1138.

12. Moore DR, Robinson MJ, Fry JL, et al. Ingested protein dose response of muscle and albumin protein synthesis after resistance exercise in young men. Am J Clin Nutr. 2009;89(1):161-168.

13. Yang Y, Breen L, Burd NA, et al. Resistance exercise enhances myofibrillar protein synthesis with graded intakes of whey protein in older men. Br J Nutr. 2012;108(10):1780-1788.

14. Peterson MD, Rhea MR, Sen A, Gordon PM. Resistance exercise for muscular strength in older adults: a meta-analysis. Ageing Res Rev. 2010;9(3):226-237.

15. Liu C-J, Latham NK. Progressive resistance strength training for improving physical function in older adults. Cochrane Database Syst Rev. 2009;(3):CD002759.

16. Kryger AI, Andersen JL. Resistance training in the oldest old: consequences for muscle strength, fiber types, fiber size, and MHC isoforms. Scand J Med Sci Sports. 2007;17(4):422-430.

17. Leenders M, Verdijk LB, Van der Hoeven L, et al. Protein supplementation during resistance-type exercise training in the elderly. Med Sci Sports Exerc. 2013;45(3):542-552.

18. Verdijk LB, Jonkers RAM, Gleeson BG, et al. Protein supplementation before and after exercise does not further augment skeletal muscle hypertrophy after resistance training in elderly men. Am J Clin Nutr. 2009; 89(2):608-616.

19. Bemben MG, Witten MS, Carter JM, Eliot KA, Knehans AW, Bemben DA.The effects of supplementation with creatine and protein on muscle strength following a traditional resistance training program in middle-aged and older men. J Nutr Health Aging. 2010; 14(2):155-159.

20. American College of Sports Medicine; Chodzko-Zajko WJ, Proctor DN, Fiatarone Singh MA, et al. American College of Sports Medicine position stand. Exercise and physical activity for older adults. Med Sci Sports Exerc. 2009;41(7):1510-1530.

21. Avila-Funes JA, Gray-Donald K, Payette H. Medición de las capacidades físicas de adultos mayores de Quebec: un análisis secundario del estudio NuAge [Measurement of physical capacities in the elderly: a secondary analysis of the Quebec longitudinal study NuAge]. Salud Publica Mex. 2006;48(6):446-454. Spanish. 
22. Mahoney FI, Barthel DW. Functional evaluation: the Barthel Index. Md State Med J. 1965;14:61-65.

23. Vellas B, Guigoz Y, Garry PJ, et al. The Mini Nutritional Assessment (MNA) and its use in grading the nutritional state of elderly patients. Nutrition. 1999;15(2):116-122.

24. Alonso J, Prieto L, Antó JM. La versión española del SF-36 Health Survey (Cuestionario de Salud SF-36): un instrumento para la medida de los resultados clínicos [The Spanish version of the SF-36 Health Survey (the SF-36 health questionnaire): an instrument for measuring clinical results]. Med Clin (Barc). 1995;104(20):771-776. Spanish.

25. Martinez J, Onis MC, Dueñas R, Albert C, Aguado C, Luque R. Versión española del cuestionario de Yesavage abreviado (GDS) para el despistaje de depresión en mayores de 65 años: adaptación y validación [The Spanish version of the Yesavage abbreviated questionnaire (GDS) to screen depressive dysfunctions in patients older than 65 years: adaptation and validation]. Medifam. 2002;12:620-630.

26. Verbeke G, Molenberghs G. Linear Mixed Models for Longitudinal Data. 2nd ed. New York, NY: Springer-Verlag; 2000.

27. Wall BT, Hamer HM, de Lange A, et al. Leucine co-ingestion improves post-prandial muscle protein accretion in elderly men. Clin Nutr. 2013;32(3):412-419.

28. Baptista IL, Silva WJ, Artioli GG, et al. Leucine and HMB differentially modulate proteasome system in skeletal muscle under different sarcopenic conditions. PLoS One. 2013;8(10):e76752.

29. Pereira MG, Baptista IL, Carlassara EO, Moriscot AS, Aoki MS, Miyabara EH. Leucine supplementation improves skeletal muscle regeneration after cryolesion in rats. PLoS One. 2014;9(1):e85283.

30. Dardevet D, Sornet C, Balage M, Grizard J. Stimulation of in vitro rat muscle protein synthesis by leucine decreases with age. $J$ Nutr. 2000;130(11):2630-2635.

31. Verhoeven S, Vanschoonbeek K, Verdijk LB, et al. Long-term leucine supplementation does not increase muscle mass or strength in healthy elderly men. Am J Clin Nutr. 2009;89(5):1468-1475.

32. Leenders M, Verdijk LB, van der Hoeven L, et al. Prolonged leucine supplementation does not augment muscle mass or affect glycemic control in elderly type 2 diabetic men. $J$ Nutr. 2011;141(6):1070-1076.

33. Godard MP, Williamson DL, Trappe SW. Oral amino-acid provision does not affect muscle strength or size gains in older men. Med Sci Sports Exerc. 2002;34(7):1126-1131.
34. Kim HK, Suzuki T, Saito K, et al. Effects of exercise and amino acid supplementation on body composition and physical function in community-dwelling elderly Japanese sarcopenic women: a randomized controlled trial. J Am Geriatr Soc. 2012;60(1):16-23.

35. Ispoglou T, King RF, Polman RCJ, Zanker C. Daily L-leucine supplementation in novice trainees during a 12-week weight training program. Int J Sports Physiol Perform. 2011;6(1):38-50.

36. Vieillevoye S, Poortmans JR, Duchateau J, Carpentier A. Effects of a combined essential amino acids/carbohydrate supplementation on muscle mass, architecture and maximal strength following heavy-load training. Eur J Appl Physiol. 2010;110(3):479-488.

37. Brooks N, Cloutier GJ, Cadena SM, et al. Resistance training and timed essential amino acids protect against the loss of muscle mass and strength during 28 days of bed rest and energy deficit. J Appl Physiol. 2008;105(1):241-248.

38. Moritani T, DeVries HA. Potential for gross muscle hypertrophy in older men. J Gerontol. 1980;35(5):672-682.

39. Magne H, Savary-Auzeloux I, Migné C, et al. Contrarily to whey and high protein diets, dietary free leucine supplementation cannot reverse the lack of recovery of muscle mass after prolonged immobilization during ageing. J Physiol. 2012;590(Pt 8):2035-2049.

40. Cermak NM, Res PT, de Groot LC, Saris WH, van Loon LJ. Protein supplementation augments the adaptive response of skeletal muscle to resistance-type exercise training: a meta-analysis. Am J Clin Nutr. 2012;96(6):1454-1464.

41. Nelson ME, Layne JE, Bernstein MJ, et al. The effects of multidimensional home-based exercise on functional performance in elderly people. J Gerontol A Biol Sci Med Sci. 2004;59(2):154-160.

42. Krist L, Dimeo F, Keil T. Can progressive resistance training twice a week improve mobility, muscle strength, and quality of life in very elderly nursing-home residents with impaired mobility? A pilot study. Clin Interv Aging. 2013;8:443-448.

43. Bauer J, Biolo G, Cederholm T, et al. Evidence-based recommendations for optimal dietary protein intake in older people: a position paper from the PROT-AGE Study Group. J Am Med Dir Assoc. 2013;14(8):542-559.

44. Zermansky AG, Alldred DP, Petty DR, Raynor DK. Striving to recruit: the difficulties of conducting clinical research on elderly care home residents. J R Soc Med. 2007;100(6):258-261.
Clinical Interventions in Aging

\section{Publish your work in this journal}

Clinical Interventions in Aging is an international, peer-reviewed journal focusing on evidence-based reports on the value or lack thereof of treatments intended to prevent or delay the onset of maladaptive correlates of aging in human beings. This journal is indexed on PubMed Central, MedLine,

\section{Dovepress}

CAS, Scopus and the Elsevier Bibliographic databases. The manuscript management system is completely online and includes a very quick and fair peer-review system, which is all easy to use. Visit http://www.dovepress. com/testimonials.php to read real quotes from published authors. 